\title{
ASPEK PENGETAHUAN DAN SIKAP MASYARAKAT TERHADAP PENGELOLAAN SAMPAH RUMAH TANGGA DI DESA MUNTOI
}

\section{The Aspects of Knowledge and Attitude of the Community Towards Households Waste Management in Muntoi Village}

\author{
Hairil Akbar ${ }^{*}$, Sarman $^{2}$, Antonius Adolf Gebang ${ }^{3}$ \\ ${ }^{1,2}$ Program Studi Kesehatan Masyarakat Institut Kesehatan dan Teknologi Graha Medika \\ ${ }^{3}$ Program Studi Keperawatan Universitas Nusa Nipa Maumere
}

"Korespondensi: hairilakbar@stikesgrahamedika.ac.id

\begin{abstract}
ABSTRAK
Masalah sampah menjadi masalah lingkungan yang mendapat perhatian khusus dari berbagai pihak. Hal ini dikarenakan jumlah timbunan sampah terus meningkat. Jumlah peningkatan timbunan sampah di Indonesia pada tahun 2015 telah mencapai 175.000 ton/hari atau setara 64 juta ton/tahun. Pengelolaan sampah rumah tangga yang ada di Desa Muntoi adalah langsung di buang lahan kosong, selokan dan samping rumah, padahal membuang sampah bukan pada tempat pembuangan sementara (TPS) dapat memberikan dampak negatif dari segi kesehatan maupun estetika lingkungan masyarakat, serta tidak adanya sarana dan prasarana yang memadai untuk penampungan sampah rumah tangga. Tujuan penelitian untuk menganalisis hubungan pengetahuan dan sikap masyarakat terhadap pengelolaan sampah rumah tangga di Desa Muntoi. Jenis penelitian ini yaitu observasional analitik dan menggunakan desain studi cross sectional, dengan jumlah sampel 94 responden yang dipilih secara simple random sampling. Data di analisis menggunakan uji Chi-square. Hasil penelitian bahwa pengetahuan $(\mathrm{p}=0,001)$ dan sikap $(\mathrm{p}=0,037)$ masyarakat berhubungan dengan pengelolaan sampah rumah tangga. Kesimpulan terdapat hubungan pengetahuan dan sikap masyarakat dengan pengelolaan sampah rumah tangga di Desa Muntoi Kabupaten Bolaang Mongondow. Diharapkan masyarakat untuk aktif melaksanakan kebersihan lingkungan disekitarnya agar terhindar dari masalah penyakit yang disebabkan oleh sampah yang tidak diolah dengan baik.
\end{abstract}

Kata kunci: Pengetahuan, sikap, pengelolaan sampah

\section{ABSTRACT}

The waste problem is an environmental problem that has received special attention from various parties. This is because the amount of landfill continues to increase. The number of increased waste piles in Indonesia in 2015 has reached 175,000 tonnes / day or the equivalent of 64 million tonnes / year. The management of household waste in Muntoi Village is directly disposed of empty land, ditches and beside houses, even though disposing of garbage not at a temporary disposal site can have a negative impact in terms of health and aesthetics of the community environment, as well as the absence of adequate facilities and infrastructure for household waste collection. The research objective was to analyze the relationship between knowledge and attitudes of the community towards household waste management in Muntoi Village. This type of research used a cross sectional design, with a sample size of 94 respondents who were selected by simple random sampling. Data analysis used the Chi-square test. The result shows that the community's knowledge $(p=0.001)$ and attitude ( $p$ $=0.037)$ are related to household waste management. The conclusion is that there is a relationship between community knowledge and attitudes with household waste management in Muntoi Village, Bolaang Mongondow Regency. It is hoped that the community will actively carry out the cleanliness of the surrounding environment in order to avoid disease problems caused by improperly processed waste.

Keywords: Knowledge, attitude, waste management 


\section{PENDAHULUAN}

Kesehatan merupakan hak asasi manusia dan sekaligus merupakan investasi sumber daya manusia, serta memiliki kontribusi yang besar untuk meningkatkan Indeks Pembangunan Manusia (IPM) (Akbar, 2020). Derajat kesehatan masyarakat ditentukan oleh kondisi pejamu, agent (penyebab penyakit), dan lingkungan. Faktor lingkungan merupakan unsur penentu kesehatan masyarakat. Apabila terjadi perubahan lingkungan di sekitar manusia, maka akan terjadi perubahan pada kondisi kesehatan lingkungan masyarakat tersebut (Mukono, 2006).

Sampah adalah bahan ataubenda padat yang terjadi akibataktifitas manusia yang tidak terpakailagi, tidak disenangi dan dibuangdengan cara saniter, kecuali yangberasal dari tubuh manusia (Akbar, 2019). Masalah sampah menjadi masalah lingkungan yang mendapat perhatian khusus dari berbagai pihak. Hal tersebut dikarenakan jumlah timbulan sampah terus meningkat seiring dengan meningkatnya jumlah penduduk (Triana, Srisantyorini, 2018). Faktor lain yang menyebabkan permasalahan sampah di Indonesia semakin rumit adalah meningkatnya taraf hidup masyarakat, yang tidak disertai dengan keselarasan pengetahuan tentang persampahan dan juga partisipasi masyarakat yang kurang untuk memelihara kebersihan dan membuang sampah pada tempatnya (Sahil et al., 2016). Dari segi jumlah dan jenis, sampah menjadi masalah yang semakin hari semakin meningkat sejalan dengan jumlah penduduk, tingkat aktivitas, pola kehidupan, tingkat sosial ekonomi, serta kemajuan teknologi yang semakin bertambah (Ririn Setyowati, 2013).

Undang-undang nomor 18 tahun 2008 tentang Pengelolaan Sampah telah berusia lebih dari sepuluh tahun. Tetapi, hingga saat ini, persoalan sampah tetap saja menjadi masalah yang serius, tak terkecuali, di Kabupaten Bolaang Mongondow. Dinas Lingkungan Hidup (DLH) Bolaang Mongondow mencatat, tahun 2019 ini, masyarakat daerah lumbung padi di Sulawesi Utara itu memproduksi 174,12 ton sampah setiap harinya. Atau setara 63.500 ton per tahun. Angka ini belum termasuk sampah yang masih di buang secara sembarangan di daerah aliran sungai dan lokasi lainnya selain tempat pembuangan sampah (Buol, 2019).

Desa Muntoi merupakan desa yang sepanjang desanya di lalui jalan yang menghubungkan antar kabupaten/kota.Hal ini memperkuat bahwa potensi menumpuknya sampah yang di buang oleh orang tidak bertanggung jawab dari dalam mobil semakin meningkatkan jumlah sampah.

Tanpa kesedaran setiap anggota keluarga untuk mengelola sampah plastik dengan pemilahan sebagai langkah awal mendaur ulang, menggunakan kembali sampah plastik sehingga mengurangi penggunaan sampah plastik maka akan berakibat kerusakan lingkungan seperti kerusakan lingkungan dan air tanah. Dalam jangka panjang, asap hasil pembakaran sampah plastik juga mengganggu kesehatan, racun yang terakumulasi di dalam 
tubuh akan menimbulkan gangguan kesehatan seperti kanker, kerusakan hormon, dan cacat janin. Selain itu, pada musim penghujan sampah plastik yang dibuang sembarangan di lingkungan sekitar membentuk cekungan dan terisi air hujan, menyebabkan sumber penyakit, akibat perkembangbiakan nyamuk vektor DBD dan malaria (Ririn Setyowati, 2013). Tujuan penelitian ini menganalisis pengetahuan dan sikap masyarakat terhadap pengelolaan sampah rumah tangga di Desa Muntoi Kabupaten Bolaang Mongondow.

\section{BAHAN DAN METODE}

Penelitian ini merupakan penelitian observasional analitik dengan desain Cross sectional. Penelitian dilakukan di daerah Desa Muntoi Kabupaten Bolaang Momgondow. Penelitian ini dilakukan pada bulan November 2020. Populasi dalam penelitian ini adalah Seluruh Kepala Rumah Tangga yang tinggal di daerah Desa Muntoi dan jumlah sampel sebanyak 94 responden. Instrumen pengambilan data menggunakan kuesioner dan lembar observasi. Teknik pengambilan sampel Simple random sampling dan analisis data menggunakan uji Chi-square.

\section{HASIL}

\section{Analisis Univariat}

Berdasarkan pada Tabel 1 menunjukkan pengetahuan masyarakat yang baik mengenai pengelolaan sampah rumah tangga sebanyak 48 responden $(51,1 \%)$ dan yang kurang baik sebanyak 46 responden $(48,9 \%)$. Distribusi sikap responden mengenai pengelolaan sampah rumah tangga yang baik sebanyak 60 responden $(63,8 \%)$ dan yang kurang baik sebanyak 34 responden (36,2\%). Distribusi pengelolaan sampah rumah tangga yang memenuhi syarat sebanyak 41 responden $(43,6 \%)$ dan yang tidak memenuhi syarat sebanyak 53 responden $(56,4 \%)$.

Tabel 1.

Distribusi Frekuensi Variabel Penelitian

\begin{tabular}{lcc}
\hline \multicolumn{1}{c}{ Variabel } & n & $\mathbf{\%}$ \\
\hline Pengetahuan & & \\
$\quad$ Baik & 48 & 51,1 \\
$\quad$ Kurang & 46 & 48,9 \\
Sikap & & \\
$\quad$ Baik & 60 & 63,8 \\
$\quad$ Kurang & 34 & 36,2 \\
Pengelolaan Sampah & & \\
$\quad$ Memenuhi syarat & 41 & 43,6 \\
$\quad$ Tidak memenuhi & 53 & 56,4 \\
$\quad$ syarat & & \\
Jumlah & 94 & 100,0 \\
\hline Sumber: Data Primer, 2020 &
\end{tabular}

\section{Analisis Bivariat}

Berdasarkan Tabel 2 menunjukkan bahwa hasil uji Chi-square variabel pengetahuan $(\rho$ value $=0,037)$ dan sikap $(\rho$ value $=0,037$ ), sehingga dapat disimpulkan bahwa ada hubungan aspek pengetahuan dan sikap masyarakat terhadap pengelolaan sampah rumah tangga di Desa Muntoi.

\section{PEMBAHASAN}

Hubungan yang bermakna didapatkan antara pengetahuan masyarakat terhadap pengelolaan sampah rumah tangga di Desa 
http://journal.unpacti.ac.id/index.php/JPP

Muntoi dengan nilai ( $\rho$ value $=0,001)$.

Berdasarkan temuan yang didapatkan pada saat penelitian pengetahuan masyarakat mengenai pengeloaan sampah masih kurang mengenai cara mengelola sampah rumah tangga yang memenuhi syarat, dan kurang dilakukan sosialisasi atau pelatihan mengenai cara pengelolaan sampah rumah tangga.

Tabel 2.

\begin{tabular}{|c|c|c|c|c|c|c|c|}
\hline \multirow{3}{*}{ Variabel } & \multicolumn{4}{|c|}{ Pengelolaan Sampah Rumah Tangga } & \multirow{2}{*}{\multicolumn{2}{|c|}{ Total }} & \multirow{3}{*}{ p value } \\
\hline & \multicolumn{2}{|c|}{ Baik } & \multicolumn{2}{|c|}{ Kurang } & & & \\
\hline & $\mathbf{n}$ & $\%$ & $\mathbf{n}$ & $\%$ & $\mathbf{n}$ & $\%$ & \\
\hline \multicolumn{8}{|l|}{ Pengetahuan } \\
\hline Baik & 29 & 60,4 & 19 & 39,6 & 48 & 100 & \multirow[t]{2}{*}{0,001} \\
\hline Kurang & 12 & 26,1 & 34 & 73,9 & 46 & 100 & \\
\hline \multicolumn{8}{|l|}{ Sikap } \\
\hline Baik & 31 & 51,7 & 29 & 48,3 & 60 & 100 & \multirow{3}{*}{0,037} \\
\hline Kurang & 10 & 29,4 & 24 & 70,6 & 34 & 100 & \\
\hline Jumlah & 41 & 43,6 & 53 & 56,4 & 94 & 100 & \\
\hline
\end{tabular}

Sumber: Data Primer, 2020

Penelitian ini sejalan dengan (Syam, 2016) menyatakan bahwa pengetahuan masyarakat berhubungan dengan pengelolaan sampah dengan nilai ( $\rho$ value $=0,00)$. Selain itu juga sejalan dengan penelitian (Susanto et al., 2010) menyatakan hasil penghitungan teknik analisa data menunjukkan corelation coeficient sebesar 1.000 dengan nilai signifikan. Dapat disimpulkan berarti H1 diterima atau ada hubungan antara tingkat pengetahuan terhadap pengelolaan sampah organik dan non organik dengan pengelolaannya pada warga RW 03 Sumbesari Malang.

Pengetahuan sangat erat hubungannya dengan pendidikan, dimana diharapkan bahwa dengan pendidikan yang tinggi maka orang tersebut akan semakin luas pula pengetahuannya. Akan tetapi perlu ditekankan, bukan berarti seseorang yang berpendidikan rendah mutlak berpengetahuan rendah pula. Hal ini mengingat bahwa peningkatan pengetahuan tidak mutlak diperoleh dari pendidikan formal saja, akan tetapi dapat diperoleh melalui pendidikan non formal. Pengetahuan seseorang tentang suatu objek mengandung dua aspek yaitu aspek positif dan aspek negatif. Sementara masyarakat yang mempunyai pengetahuan kurang baik tentang pengelolaan sampah, disebabkan karena kurangnya kemampuan mereka merespon tentang pernyataan melalui kuesioner yang diberikan oleh peneliti, dan kurangnya informasi yang mereka dapatkan tentang pengelolaan sampah. 
http://journal.unpacti.ac.id/index.php/JPP

Hubungan yang bermakna didapatkan antara sikap masyarakat terhadap pengelolaan sampah rumah tangga di Desa Muntoi dengan nilai $(\rho$ value $=0,037)$. Hal ini disebabkan bahwa masih banyak masyarakat yang memiliki sikap untuk membuang sampah rumah tangganya dibandingkan untuk dikelola kembali. Hal ini dikarenakan pengaruh dari minimnya pengetahuan masyarakat terkait cara pengelolaan sampah rumah tangga yang memeuni syarat. Pengetahuan dan sikap masyarakat tersebut tidak terpisahkan sehingga masih saling berhubungan satusama lain.

Penelitian ini sejalan dengan (Luluk, 2019) menyatakan bahwa sikap berhubungan perilaku pengelolaan sampah ( $\rho$ value $0,009<$ 0,05) pada ibu rumah tangga di Desa Gisikcemandi Sidaorjo. Selain itu juga sejalan dengan penelitian (Syam, 2016) menyatakan ada hubungan yang bermakna antara sikap dengan pengelolaan sampah, hal ini berdasarkan uji statistic yang dilakukan dengan hasil ( $\rho$ value $(0.000)<\alpha(0.05)$.

Dalam sikap positif, kecenderungan tindakan adalah mendekati, menyenangi, mengharapkan objek tertentu. Pembentukan sikap dipengaruhi oleh beberapa faktor yakni pengalaman pribadi, kebudayaan, orang lain yang dianggap penting, media masa, lembaga pendidikan dan lembaga agama, dan faktor emosional. Sikap yang tidak baik bisa disebabkan oleh kurangnya pengetahuan tentang pengolahan sampah yang baik. Hal ini sejalan dengan penelitian yang dilakukan oleh menyatakan informasi atau pengetahuan adalah syarat penting bagi sikap, jadi sikap bukan hanya perasaan mendukung atau tidak mendukung perilaku, namun juga menyangkut estimasi akan hasil dari perilaku tersebut (Sangga Saputra N.A, 2017).

\section{KESIMPULAN DAN SARAN}

Aspek pengetahuan dan sikap masyarakat berhubungan terhadap pengelolaan sampah rumah tangga di Desa Muntoi. Disarankan responden untuk aktif melaksanakan kebersihan lingkungan disekitarnya agar terhindar dari masalah penyakit yang disebabkan oleh sampah yang tidak diolah dengan baik.

\section{DAFTAR PUSTAKA}

Akbar, H. (2019). Determinan EpidemiologisKejadian Diare Pada Anak Balita di Wilayah Kerja Puskesmas Juntinyuat. Jurnal Ilmiah Keperawatan Stikes Hang Tuah Surbaya, 13(2), 91101.

Akbar, H. (2020). Hubungan Karakteristik Ibu terhadap Praktik Keluarga Sehat (Studi Kasus di Desa Muntoi Kabupaten Bolaang Mongondow). Jurnal Info Kesehatan, 10(1), 214-218.

Buol, R. A. (2019). Tiap Hari, Bolmong Produksi 174 Ton Sampah. Zonautara.Com.

Luluk, M. (2019). Hubungan Tingkat Pengetahuan dan Sikap Dengan Perilaku Pengelolaan Sampah pada Ibu Rumah Tangga di Desa Gisik Cemandi Sidoarjo. Universitas Nahdlatul Ulama Surabaya.

Mukono, H. (2006). Prinsip Dasar Kesehatan Lingkungan Edisi Kedua. Airlangga University Press.

Ririn Setyowati, S. A. M. (2013). Pengetahuan 
http://journal.unpacti.ac.id/index.php/JPP

dan Perilaku Ibu Rumah Tangga dalam Pengelolaan Sampah Plastik. Kesmas, Jurnal Kesehatan Masyarakat Nasiona, $7(12)$.

Sahil, J., Henie, M., Al, I., Rohman, F., \& Syamsuri, I. (2016). Sistem Pengelolaan dan Upaya Penanggulangan Sampah Di Kelurahan Dufa- Dufa Kota Ternate. Jurnal BIOeduKASI, 4(2), 478-487.

Sangga Saputra N.A, S. A. M. (2017). Pengetahuan, Sikap, dan Perilaku Pengelolaan Sampah pada Karyawan di Kampus. Kes Mas: Jurnal Kesehatan Masyarakat, 11(1), 22-27.

Susanto, R., M, N. L., \& Pahroni, R. (2010).
Hubungan Pengetahuan Terhadap Pengelolaan Sampah Organik dan Non Organik Pada Masyarakat RW 03 Sumbersari Malang. Jurnal Keperawatan, 1(1), 32-38.

Syam, D. M. (2016). Hubungan Pengetahuan dan Sikap Masyarakat Dengan Pengelolaan Sampah di Desa Loli Tasiburi Kecamatan Banawa Kabupaten Donggala. HIGIENE, 2(1).

Triana, Srisantyorini, F. K. N. (2018). Pengetahuan, Sikap dan Perilaku Ibu Rumah Tangga Terhadap. Jurnal Kedokteran Dan Kesehatan, 14(2), 6573. 